\title{
QTL analysis for resistance to foliar damage caused by Thrips tabaci and Frankliniella schultzei (Thysanoptera: Thripidae) feeding in cowpea [Vigna unguiculata (L.) Walp.]
}

\author{
Wellington Muchero · Jeffrey D. Ehlers · \\ Philip A. Roberts
}

Received: 9 January 2009/Accepted: 15 June 2009/Published online: 7 July 2009

(C) The Author(s) 2009. This article is published with open access at Springerlink.com

\begin{abstract}
Three quantitative trait loci (QTL) for resistance to Thrips tabaci and Frankliniella schultzei were identified using a cowpea recombinant inbred population of $127 \mathrm{~F}_{2: 8}$ lines. An amplified fragment length polymorphism (AFLP) genetic linkage map and foliar feeding damage ratings were used to identify genomic regions contributing toward resistance to thrips damage. Based on Pearson correlation analysis, damage ratings were highly correlated $(r \geq 0.7463)$ across seven field experiments conducted in 2006, 2007, and 2008. Using the KruskallWallis and Multiple-QTL model mapping packages of MapQTL 4.0 software, three QTL, Thr-1, Thr-2, and $T h r-3$, were identified on linkage groups 5 and 7 accounting for between 9.1 and $32.1 \%$ of the phenotypic variance. AFLP markers ACC-CAT7, ACG-CTC5, and AGG-CAT1 co-located with QTL peaks for $T h r-1, T h r-2$, and $T h r-3$, respectively. Results of this study will provide a resource for molecular marker development and the genetic characterization of foliar thrips resistance in cowpea.
\end{abstract}

W. Muchero · P. A. Roberts $(\square)$

Nematology Department, University of California,

Riverside, CA 92521, USA

e-mail: philip.roberts@ucr.edu

W. Muchero

e-mail:wmuch001@ucr.edu

J. D. Ehlers

Botany and Plant Sciences Department, University of California, Riverside, CA 92521, USA
Keywords Cowpea - Frankliniella schultzei . Thrips tabaci - Genetic resistance · QTL analysis

\section{Introduction}

Cowpea [Vigna unguiculata (L.) Walp.] is a crop of major economic importance among resource poor farmers in sub-Saharan Africa and other parts of the world (Ehlers and Hall 1997; Timko et al. 2007). Cowpea has a wide range of uses and is grown primarily for human consumption as a dry grain legume, fresh shelled 'peas', fresh pods ('snap beans'), and fresh and dried leaves (Jackai and Daoust 1986). Although cowpea is a hardy crop that can produce reasonably well under conditions that may render other crops unproductive, production is still constrained by several biotic and abiotic stresses (Hall et al. 1997). Among these, damage by thrips (Thysanoptera, Thripidae) is one of the most important biotic stresses limiting cowpea production (Jackai and Daoust 1986). In West Africa, the flower bud thrips, Megalurothrips sjostedti is the most economically important thrips pest of cowpea causing yield losses between 20 and $70 \%$ depending on the severity of infestation (Ngakou et al. 2008). Other thrips species have been described as important pests of cowpea in West Africa and other parts of the world. These include the foliar feeding Frankliniella sp. (Bottenberg et al. 1997), Thrips palmi 
in Asia and T. tabaci in Asia and South America (Jackai and Adalla 1997). The economic impact of foliar thrips on yield has not been throughly documented in different parts of the world, however, Singh and Allen (1980) reported that damage caused by foliar thrips feeding at the seedling stage resulted in yield losses up to $15 \%$ in West Africa. More recently, damage by $T$. tabaci has been reported to cause significant yield loss of cowpea in parts of India (Singh, personal communication). However, since cowpea leaves are a major source of nutrition in eastern and southern Africa (Saidi et al. 2007), damage caused by thrips feedings results in significant reduction of market and esthetic value of the crop.

Due to their small size and non-specific feeding, thrips are well equipped for invasive behavior (Morse and Hoddle 2006). The biology of thrips makes them especially difficult to control. Adoption of a broad range of strategies that include repeat applications of expensive insecticides has been recommended. However, this often leads to rapid development of insecticide resistance in thrips populations rendering the chemical treatments ineffective (Morse and Hoddle 2006). In addition, the cost of insecticides and proper application equipment is beyond the economic means of the majority of resource-poor farmers who grow the crop. Identification and deployment of natural host plant resistance in important cultivars to manage thrips reduces or eliminates dependence on environmentally toxic chemicals that resource poor subsistence farmers cannot afford and are not well equipped to handle (Jackai and Adalla 1997). Host plant resistance has been deployed successfully against other insect pests in other crops of economic importance via traditional breeding or genetic engineering (Hilder and Boulter 1999; Christou et al. 2006). Germplasm with thrips resistance traits that can be used as sources of resistance genes for elite cultivar development has been identified in numerous crops. For example, resistant varieties have been described in cotton (Stanton et al. 1992), common bean (Cardona et al. 2002), pepper (Maris et al. 2003), and cabbage (Stoner et al. 1989). In cowpea, studies have identified sources of genetic resistance mainly against the flower bud thrips M. sjostedti (Abudulai et al. 2006; Alabi et al. 2006). Presently, no study has identified cowpea germplasm with resistance to the foliar feeding thrips species T. tabaci and Frankliniella sp.
In general, the molecular genetics of thrips resistance is not well understood. Only two quantitative trait loci (QTL) studies have been reported in cowpea and common bean. Omo-Ikerodah et al. (2008) reported the mapping of QTL mediating resistance to flower bud thrips, M. sjostedti in cowpea. In common bean, QTL were identified mediating resistance to T. palmi (Frei et al. 2005). In both cases, multi-genic resistance mechanisms were suggested with large effect QTL being reported. Because of this lack of molecular resources, no genetic markers have been developed to facilitate rapid screening for thrips resistance in cowpea and other crops. In addition, the specificity of genetic resistance mechanisms against different thrips species is not well understood, such that it is not clear if some of the resistance traits identified to date can be deployed against different thrips species. However, studies in other insect systems suggest that genetic resistance mechanisms may be highly specific to the insect species or even the developmental stage of the insect pest (Hilder and Boulter 1999; Walling 2000).

In the present study, we conducted a QTL-based analysis of cowpea resistance to feeding damage by a T. tabaci/F. schultzei complex in cowpea fields at the Coachella Valley Agricultural Research Station (CVARS) and the Citrus Research Center-Agricultural Experiment Station (CRC-AES) of the University of California-Riverside, USA. We report the identification of QTL segregating in a cowpea recombinant inbred population (RIL) associated with resistance to foliar thrips damage and AFLP markers closely associated with QTL peaks. Our findings will complement current knowledge on genetic resistance mechanisms and facilitate the development of molecular markers for use in cowpea breeding. In addition, this knowledge will be valuable in efforts to isolate the molecular genetic determinants mediating resistance against foliar feeding thrips.

\section{Materials and methods}

Plant material

A $\mathrm{F}_{2: 8^{-}}$RIL population of 127 lines derived by single seed descent from a cross between foliar thrips susceptible cowpea breeding line IT93K503-1 and resistant blackeye cowpea cultivar 'California 
Blackeye No. 46' (CB46) inbred genotypes was used in the study. IT93K503-1 is an elite breeding line developed by the International Institute of Tropical Agriculture (IITA), Ibadan, Nigeria. Seeds of the parents and RILs used in all experiments were produced under uniform greenhouse conditions.

Field-based phenotyping of thrips damage

Four field experiments were planted at CVARS $\left(33^{\circ} 37^{\prime} 52^{\prime \prime} \mathrm{N}, 116^{\circ} 06^{\prime} 43^{\prime \prime} \mathrm{W}\right)$ on August 7, 2006 (CVARS 2006); May 21, 2007 (CVARS 2007A); August 14, 2007 (CVARS 2007B); and August 20, 2008 (CVARS 2008) with 57, 126, 57, and 90 RILs, respectively. Field experiments conducted at CRCAES $\left(33^{\circ} 57^{\prime} 54^{\prime \prime} \mathrm{N} ; 117^{\circ} 20^{\prime} 08^{\prime \prime} \mathrm{W}\right)$ were planted on May 16, 2006 (CRC-AES 2006); May 22, 2007 (CRC-AES 2007); and June 17, 2008 (CRC-AES 2008) with 57, 57, and 108 RILs, respectively. The two parental genotypes were included in all experiments in addition to the RIL population.

In each experiment, four seeds were planted every $30 \mathrm{~cm}$ in 5-m-long plots set in rows $75 \mathrm{~cm}$ apart. Each genotype was replicated four times in a randomized complete block design. At CRC-AES, plots were irrigated 1 week before planting and this provided sufficient moisture for seedling emergence and development until foliar feeding damage ratings were taken. At CVARS, plots were drip-irrigated for $1 \mathrm{~h}$ immediately after planting. Thereafter, additional irrigation was provided once per week. Both $T$. tabaci and $F$. schultzei were identified from samples collected from infested cowpea plants at both locations. The thrips populations were not artificially controlled and were allowed to build up naturally to high, uniformly distributed levels after planting. Typically, 2-4 thrips per leaf were visible on young leaves of cowpea plants assessed during weeks $2-5$ of the experiments at both locations. Damage ratings were taken on 5-week-old cowpea plants using a rating scale of 1-10 as described by Cardona et al. (2002). Feeding by the thrips on susceptible plants caused the characteristic scarring along the mid-rib of affected leaves resulting in curled and distorted leaflets (Fig. 1).

Genetic linkage mapping

The amplified fragment length polymorphism (AFLP)-based genetic linkage map used in this study was constructed using $127 \mathrm{~F}_{2: 8}$ RIL developed from a cross between IT93K503-1 and CB46 and is described in Muchero et al. (2009). Briefly, the map was constructed with the Joinmap 3.0 program (Van Ooijen and Voorrips 2001) using 306 AFLP markers distributed over eleven linkage groups spanning a total genetic distance of $643 \mathrm{cM}$.

QTL analysis

The Multiple-QTL model mapping (MQM) and Kruskall-Wallis packages of the MapQTL 4.0 software (Van Ooijen et al. 2002) were used to reveal QTL regions using thrips-damage rating data from individual field experiments. LOD significance thresholds were determined for each linkage group using 1,000 permutations at the 0.05 significance level. QTL significance in the Kruskall-Wallis analysis was based on the 0.005 significance level suggested by authors of the software (Van Ooijen et al. 2002). Adjacent QTL were considered distinct and separate when there was a drop of one in LOD scores between QTL peaks over multiple experiments (Posthuma et al. 2005). Graphical QTL representation was carried out using the MapChart 2.2 software (Voorrips 2002).

\section{Statistical analysis}

Pearson correlation analysis and construction of frequency distributions was carried out using the Statistix 8 software (Analytical Software 2003). Analysis of variance (ANOVA) was conducted with the Proc GLM procedure of the SAS software (19891996, SAS Institute, Inc, Cary, NC). ANOVA and frequency distribution analysis were conducted using data from experiments CVARS 2007A, CRC-AES 2008, CVARS 2008, and CRC-AES 2007 in which 126, 108, 90, and 57 RILs, respectively, were evaluated for response to thrips feeding.

\section{Results}

Field-based phenotyping of thrips damage

High and uniform levels of thrips infestation were recorded in all experiments, resulting in distinct 

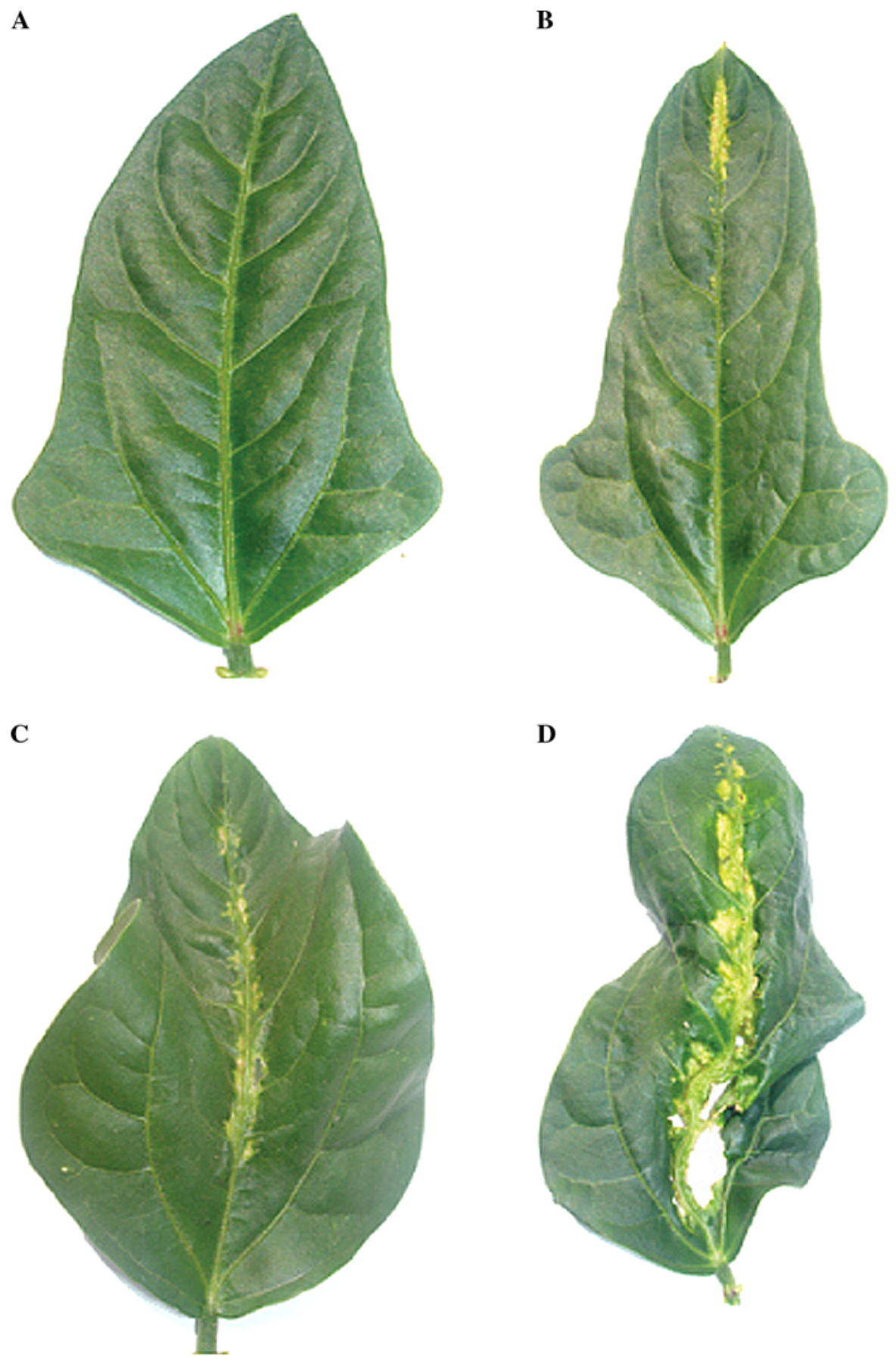

Fig. 1 Damage along the mid-rib and leaf deformation observed in response to foliar feeding by a complex of Thrips tabaci and Frankliniella schultzei thrips species in a cowpea recombinant inbred population derived from a cross between

susceptibility and resistance responses to feeding among cowpea genotypes, as represented in Fig. 1. Foliar damage ratings from all seven field

susceptible cowpea genotype IT93K503-1 and resistant genotype CB46. a Highly resistant (thrips damage score $=0$ ), b Moderately resistant (score $=2$ ), c Moderately susceptible $($ score $=6)$, and $\mathbf{d}$ Highly susceptible (score $=10$ ) phenotypes

experiments conducted over 3 years were highly correlated ( $r \geq 0.7463, P=0.0000$; Table 1$)$. Frequency distributions of phenotypic data deviated 
Table 1 Results of Pearson correlation analysis of foliar damage induced by thrips feeding in seven field experiments conducted using a cowpea recombinant inbred population developed from a cross between foliar thrips susceptible IT93K503-1 and resistant CB46 genotypes

\begin{tabular}{|c|c|c|c|c|c|c|}
\hline & CRC-AES 2006 & CVARS 2006 & CRC-AES 2007 & CVARS 2007A & CVARS 2007B & CRC-AES 2008 \\
\hline \multicolumn{7}{|l|}{ CRC-AES 2006} \\
\hline CVARS 2006 & 0.8375 & & & & & \\
\hline CRC-AES 2007 & 0.9198 & 0.7951 & & & & \\
\hline CVARS 2007A & 0.8577 & 0.7493 & 0.9374 & & & \\
\hline CVARS 2007B & 0.9265 & 0.7463 & 0.9668 & 0.9121 & & \\
\hline CRC-AES 2008 & 0.9395 & 0.7680 & 0.9619 & 0.9926 & 0.9074 & \\
\hline CVARS 2008 & 0.9675 & 0.8119 & 0.9524 & 0.9313 & 0.9596 & 0.9671 \\
\hline
\end{tabular}

All correlation results were significant at $P=0.0000$
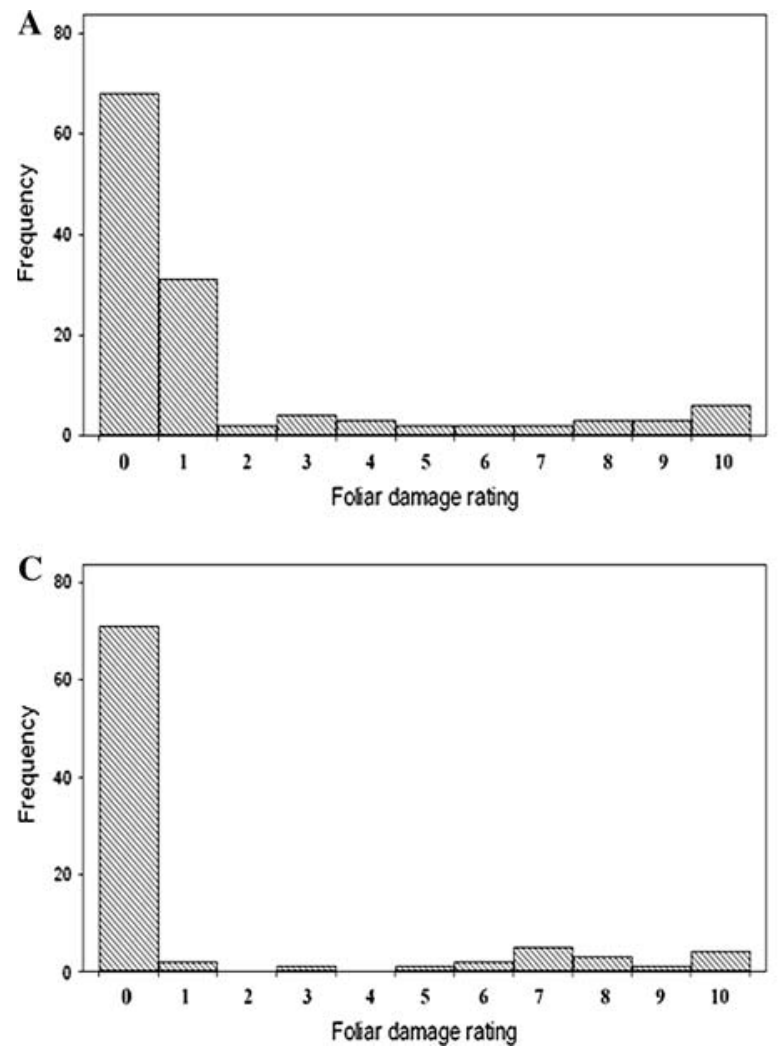

Fig. 2 Frequency distributions of foliar damage ratings in response to thrips feeding taken from field experiments a CVARS 2007A, b CRC-AES 2008, c CVARS 2008, and d CRC-AES 2007 conducted with 126, 108, 90, and 57

from normality and were skewed toward the resistant phenotype (Fig. 2a-d). The resistant parent genotype CB46 exhibited no visible symptoms of feeding damage (mean rating $=0$ ) whereas the susceptible parent IT93K503-1 exhibited significant feeding
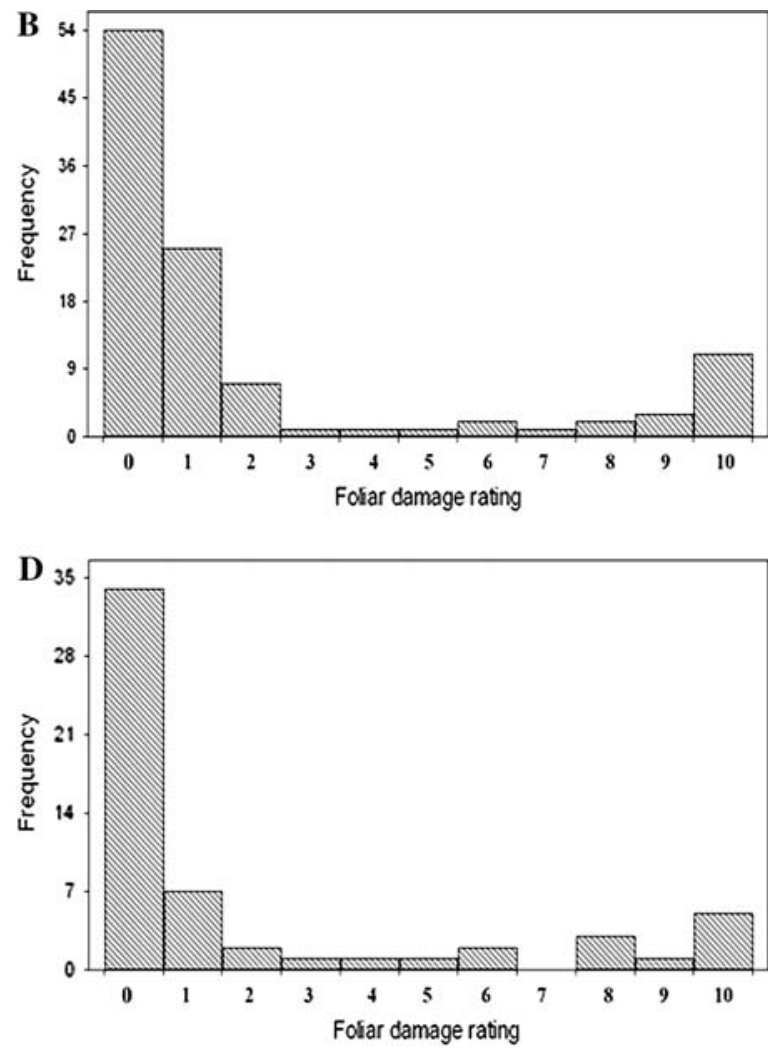

recombinant inbred lines (RILs), respectively. RILs were developed from a cross between susceptible IT93K503-1 and resistant CB46 genotypes

damage (mean rating $=6.625 \pm 0.212 \mathrm{SE}$ ) across experiments. The clear differences between parental genotypes and RILs in response to thrips feeding are summarized in Table 2 which shows mean ratings observed across four experiments. These differences 
Table 2 Mean ratings ( \pm standard error) of foliar damage caused by thrips feeding on cowpea and $F$ values for four field experiments conducted with recombinant inbred lines (RILs) developed from a cross between susceptible IT93K503-1 and resistant CB46 genotypes

\begin{tabular}{lcccr}
\hline Experiment & IT93K503-1 mean rating & CB46 mean rating & Range of mean ratings in RILs & $F$ value \\
\hline CVARS 2007A (126) & $7 \pm 0.71$ & 0 & $0-10$ & $21.02 * * * *$ \\
CRC-AES 2008 (108) & $6.25 \pm 0.48$ & 0 & $0-10$ & $85.50 * * * *$ \\
CVARS 2008 (90) & $8 \pm 0.41$ & 0 & $0-10$ & $92.79 * * * *$ \\
CRC-AES 2007 (57) & $6.25 \pm 0.49$ & 0 & $0-10$ & $23.63 * * * *$ \\
\hline
\end{tabular}

Values in parentheses indicate the number of RILs evaluated in each experiment

**** Significant at the 0.0001 level

were confirmed by ANOVA, in which $F$ values for genotypic differences were highly significant $(P=0.0001$; Table 2) and coefficient of variation (CV) ranged from 16.5 to $28.6 \%$ for parental genotypes and from 40.0 to $83.7 \%$ for the RILs. Transgressive segregation was observed for susceptibility in some RILs whose feeding damage ratings surpassed the susceptible parent (Table 2). RILs exhibiting intermediate and transgressive phenotypes were consistent across replicates and individual experiments, indicating that these responses were largely genetic and not artifacts of variation in thrips infestation pressure.

\section{QTL analysis}

Three QTL were identified on linkage groups 5 and 7 with high reproducibility across all seven experiments regardless of mapping population size (Table 3; Fig. 3). Both Kruskall-Wallis and MQM analysis identified the same intervals for the three QTL. All QTL met or surpassed the suggested 0.005 significance threshold for QTL detection under the Kruskall-Wallis analysis in at least three experiments (Table 3). In the MQM analysis, LOD scores for the QTL surpassed the significance thresholds in each of the seven experiments (Table 3). Two of these QTL, Thr-1 and Thr-2 mapped adjacent to each other on linkage group 5 (Fig. 3a). QTL Thr-3 mapped on linkage group 7 (Fig. 3b). All QTL peaks mapped in the same map interval regardless of the number of RILs evaluated (Table 3). The QTL peak for Thr-1 was located at position $28.4 \mathrm{cM}$ of linkage group 5 and co-located with the AFLP marker, ACC-CAT7. The $T h r-2$ peak mapped at position $53.4 \mathrm{cM}$ where it co-located with AFLP marker ACG-CTC5 (Table 3; Fig. 3a). The QTL peak for Thr-3 mapped within the same interval but the exact position of the peak differed slightly between experiments. However, the Thr-3 peak mapped to the same position in experiments CVARS 2007A, CRC-AES 2008, and CVARS 2008 in which 126, 108, and 90 RILs were evaluated. In these experiments, the Thr-3 QTL peak mapped to position $35.6 \mathrm{cM}$ over the AFLP marker AAG-CAT1 (Table 3). In general, Thr-2 explained the largest percent phenotypic variance $\left(R^{2}\right)$ over experiments $\left(16.1 \leq R^{2} \leq 32.1\right)$, followed by $T h r-3\left(14.1 \leq R^{2} \leq\right.$ 24.6). Thr-1 explained 9.1, 9.8, and $10.1 \%$ of the phenotypic variance, respectively, in experiments conducted with 126, 90, and 108 RILs (Table 3). $R^{2}$ estimates for $T h r-1$ were significantly inflated in experiments conducted with 57 RIL (data not shown). There was no statistical difference between the $R^{2}$ estimates for Thr-2 and Thr-3 based on the 57, 90, 108 , or 126 RIL populations; however, the smaller population generally gave slightly higher estimates (Table 3).

\section{Discussion}

Highly reproducible differences were observed between cowpea genotypes IT93K503-1 and CB46 in response to foliar damage caused by thrips feeding during seven field experiments conducted in Coachella Valley and Riverside, California. Genotype IT93K503-1 exhibited the scarring and foliar distortion phenotype characteristic of thrips feeding whereas genotype CB46 did not show any visible signs of this phenotype. These parental as well as transgressive susceptibility phenotypes were observed in the RIL population with high reproducibility across experiments. The robustness and consistency of these genotypic differences were 
Table 3 Summary of QTL mapping results from KruskallWallis and Multiple-QTL model mapping (MQM) analysis of foliar thrips damage ratings in a cowpea recombinant inbred

\begin{tabular}{|c|c|c|c|c|c|c|c|c|}
\hline \multirow[t]{2}{*}{ Experiment } & \multirow[t]{2}{*}{ QTL } & \multirow{2}{*}{$\begin{array}{l}\text { Linkage } \\
\text { group }\end{array}$} & \multirow{2}{*}{$\begin{array}{l}\text { QTL peak } \\
\text { position }(\mathrm{cM})\end{array}$} & \multirow{2}{*}{$\begin{array}{l}\text { Marker at } \\
\text { QTL peak }\end{array}$} & \multirow{2}{*}{$\begin{array}{l}\text { Kruskall-Wallis } \\
\text { Significance level }\end{array}$} & \multicolumn{3}{|c|}{ MQM } \\
\hline & & & & & & LOD & LOD threshold & $R^{2}$ \\
\hline CVARS 2006 (57) & Thr-1 & 5 & 28.4 & ACC-CAT7 & 0.0005 & 2.94 & 1.8 & - \\
\hline CRC-AES 2006 (57) & Thr-1 & 5 & 28.4 & ACC-CAT7 & 0.0005 & 2.44 & 1.8 & - \\
\hline CVARS 2007A (124) & $T h r-1$ & 5 & 28.4 & ACC-CAT7 & 0.005 & 2.57 & 1.8 & 9.1 \\
\hline CVARS 2007B (57) & Thr-1 & 5 & 28.4 & ACC-CAT7 & 0.005 & 3.45 & 1.8 & - \\
\hline CRC-AES 2007 (57) & Thr-1 & 5 & 28.4 & ACC-CAT7 & 0.005 & 4.01 & 1.8 & - \\
\hline CRC-AES 2008 (108) & Thr-1 & 5 & 28.4 & ACC-CAT7 & 0.01 & 2.49 & 1.8 & 10.1 \\
\hline CVARS 2008 (92) & $T h r-1$ & 5 & 28.4 & ACC-CAT7 & 0.05 & 2.02 & 1.8 & 9.8 \\
\hline CVARS 2006 (57) & $T h r-2$ & 5 & 53.4 & ACG-CTC5 & 0.0005 & 3.06 & 1.8 & 22.9 \\
\hline CRC-AES 2006 (57) & $T h r-2$ & 5 & 53.4 & ACG-CTC5 & 0.0001 & 2.91 & 1.8 & 21.2 \\
\hline CVARS 2007A (124) & $T h r-2$ & 5 & 53.4 & ACG-CTC5 & 0.0001 & 5.72 & 1.8 & 19.3 \\
\hline CVARS 2007B (57) & $T h r-2$ & 5 & 53.4 & ACG-CTC5 & 0.005 & 3.68 & 1.8 & 26.0 \\
\hline CRC-AES 2007 (57) & $T h r-2$ & 5 & 53.4 & ACG-CTC5 & 0.0001 & 4.60 & 1.8 & 32.1 \\
\hline CRC-AES 2008 (108) & $T h r-2$ & 5 & 53.4 & ACG-CTC5 & 0.0001 & 5.92 & 1.8 & 22.4 \\
\hline CVARS 2008 (92) & $T h r-2$ & 5 & 53.4 & ACG-CTC5 & 0.001 & 3.41 & 1.8 & 16.1 \\
\hline CVARS 2006 (57) & Thr-3 & 7 & 40.5 & AGG-CAT1 & 0.0005 & 2.95 & 1.9 & 21.9 \\
\hline CRC-AES 2006 (57) & $T h r-3$ & 7 & 30.7 & AGC-CTT14 & 0.05 & 2.06 & 1.9 & 23.7 \\
\hline CVARS 2007A (124) & $T h r-3$ & 7 & 35.6 & AAG-CAT1 & 0.001 & 4.08 & 1.9 & 14.1 \\
\hline CVARS 2007B (57) & $T h r-3$ & 7 & 40.5 & AGG-CAT1 & 0.01 & 2.03 & 1.9 & 15.1 \\
\hline CRC-AES 2007 (57) & $T h r-3$ & 7 & 40.5 & AGG-CAT1 & 0.0005 & 2.58 & 1.9 & 19.4 \\
\hline CRC-AES 2008 (108) & Thr-3 & 7 & 35.6 & AAG-CAT1 & 0.0005 & 4.07 & 1.9 & 15.9 \\
\hline CVARS 2008 (92) & Thr-3 & 7 & 35.6 & AAG-CAT1 & 0.0001 & 5.51 & 1.9 & 24.6 \\
\hline
\end{tabular}

$R^{2}$ values for QTL $T h r-1$ are reported for CVARS 2007A, CRC-AES 2008, and CVARS 2008

Values in parentheses indicate the number of RILs evaluated in each experiment

confirmed by highly significant correlation coefficients and $F$ values associated with damage ratings.

Based on these phenotypic observations, three QTL for resistance to a complex of T. tabaci and $F$. schultzei were expressed stably and mapped reproducibly on linkage groups 5 and 7 of the genetic map. QTL Thr-2 displayed the largest effect on the resistance phenotype followed by Thr-3 while Thr-1 had the smallest effect. Population size did not affect the statistical significance of the three QTL. In addition, the general map interval in which all three QTL mapped remained the same across experiments. Further, QTL peaks for Thr-1 and Thr-2 co-located with AFLP markers ACC-CAT7 and ACG-CTC5, respectively, on the same map position in all seven experiments. Although the map position shifted slightly for $T h r-3$, the map position was consistent population (RIL) developed from a cross between susceptible IT93K503-1 and resistant CB46 genotypes 

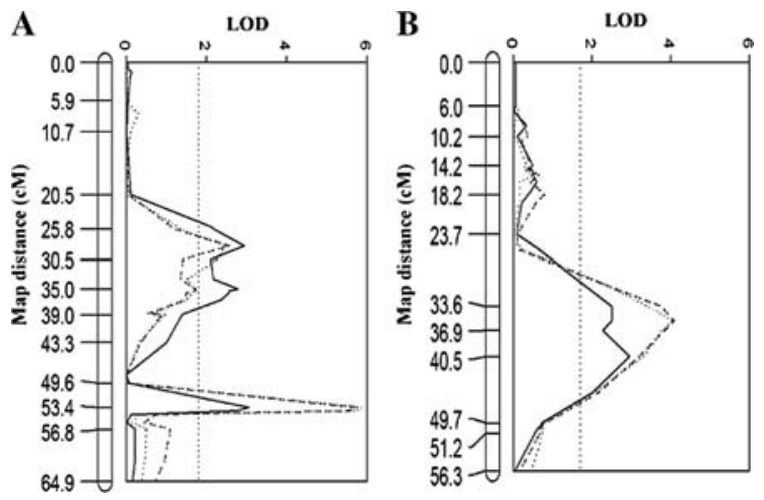

Fig. 3 LOD score traces for a Thr-1 $(28.4 \mathrm{cM})$ and $T h r-2$ $(53.4 \mathrm{cM})$ QTL on linkage group 5 and b Thr-3 QTL on linkage group 7 based on foliar thrips damage ratings collected in field experiments conducted with 57 (solid line), 108 (broken line), and 124 (dotted line) cowpea recombinant inbred lines (RILs). The RIL population was developed from a cross between susceptible IT93K503-1 and resistant CB46 genotypes

caused by small population size. In contrast, $R^{2}$ estimates for $T h r-2$ and $T h r-3$ were not statistically different between the small and larger population sizes even though the smaller population generally gave higher estimates.

Although the specificity of the resistance mechanism against different thrips species is not known at this point, the results of our study indicated that the resistance identified in the parental genotype CB46 and in the resistant RILs was highly effective against the T. tabaci and F. schultze $i$ thrips complex. This is especially true, considering the high and uniform levels of thrips infestation in all seven field experiments, in which severe foliar damage occurred in the susceptible genotypes. Based on marker profiles and mapping results, the resistance allele associated with QTL Thr-3 was derived from the susceptible parent IT93K503-1. This would explain both the intermediate behavior of the susceptible parent in response to feeding and the observed transgressive segregation for susceptibility in the RIL population. In this regard, RILs that lacked all three QTL exhibited more severe scarring and leaf distortion than the susceptible parent. Further, this observation meant that the combination of Thr-1 and Thr-2 QTL in the CB46 resistant parent was sufficient to confer highly effective resistance to both thrips species. However, the extent to which each QTL contributed toward resistance to each thrips species remains to be determined. Further investigation will be required using isolated populations of the two thrips species to ascertain the effectiveness of the resistance mechanism against individual species. The availability of RILs that carry different combinations of the three QTL resulting in the observed intermediate phenotypes provides the genetic resources necessary to test the effectiveness of different QTL combinations against each thrips species.

Consistent association between AFLP markers and QTL peaks across experiments suggested close linkage between these markers and the genetic determinants of the resistance phenotype. This provides opportunity for development of molecular markers for use in marker-assisted selection for resistance against foliar thrips. AFLP markers ACCCAT7 and ACG-CTC5 that co-located with QTL Thr-1 and Thr-2, respectively, are potential candidates for use in developing molecular markers. However, additional validation of these QTL and AFLP markers in different genetic backgrounds will be necessary to verify their robustness. The utility of molecular markers developed from these AFLP markers should be enhanced by the stability of expression of the resistance mechanism. Based on correlation analysis and QTL mapping results, expression of genetic resistance against the T. tabaci/F. schultzei population complex was highly consistent between the CVARS and CRC-AES locations over the 3 years during which seven field experiments were conducted. The negligible influence of location and environment, time, and mapping population size on the resistance mechanism suggests that the trait was highly heritable. Genotype by environment $(g \times e)$ interactions often constrain the study and practical deployment of quantitatively inherited beneficial traits in cowpea and other important crop plants (Akande 2007). Therefore, the negligible $g \times e$ interactions observed in the expression of resistance against foliar thrips in cowpea reported here suggested that this trait can be deployed effectively in elite cultivars with potential for adoption in different geographical regions where damage caused by foliar thrips limits cowpea production. Further, the close proximity of Thr-1 and Thr-2 QTL on linkage group 5 should facilitate the introgression of this QTL block as a single unit by targeting low recombination rates in breeding progenies. 
Although another genetic mapping study of resistance was conducted with cowpea exposed to the flower bud thrips $M$. sjostedti (Omo-Ikerodah et al. 2008), those findings cannot be reliably compared with results from the current study because the two studies utilized different genetic linkage maps that have not been aligned. In the $M$. sjostedti study, Omo-Ikerodah et al. (2008) identified five QTL, one of which explained $32 \%$ of the $77.5 \%$ overall phenotypic variance. Reciprocal screening of the RIL populations for resistance to foliar thrips and flower bud thrips is underway. Results from these studies should enhance our knowledge of potential genetic overlap of host resistance mechanisms against thrips species which have different tissue-specific feeding preferences in cowpea.

Results presented in this study will provide a platform for molecular marker development and further characterization of the molecular genetics of host resistance against foliar thrips in cowpea.

Acknowledgments We wish to thank Dr. Mark Hoddle for thrips species identification. This research was supported in part by the Bean/Cowpea Collaborative Research Support Program (USAID Grant no. GDG-G-00-02-00012-00) and the CGIAR Generation Challenge Program. The opinions and recommendations herein are those of the authors and not necessarily those of the funding agencies.

Open Access This article is distributed under the terms of the Creative Commons Attribution Noncommercial License which permits any noncommercial use, distribution, and reproduction in any medium, provided the original author(s) and source are credited.

\section{References}

Abudulai M, Salifu AB, Haruna M (2006) Screening of cowpeas for resistance to the flower bud thrips, Megalurothrips sjostedti Trybom (Thysanoptera: Thripidae). J Appl Sci 6:1621-1624. doi:10.3923/jas.2006.1621.1624

Akande SR (2007) Genotype by environment interaction for cowpea seed yield and disease in the forest and derived savanna agro-ecologies of South-West Nigeria. Am-Eurasian J Agric Environ Sci 2:163-168

Alabi OY, Odebiyi JA, Tamò M (2006) The relationship between primary metabolites in reproductive structures of cowpea Vigna unguiculata (Fabaceae: Papilionidae) cultivars and field resistance to the flower bud thrips $\mathrm{Meg}$ alurothrips sjostedti (Thysanoptera: Thripidae). Int J Trop Insect Sci 26:8-15

Analytical software (2003) Statistix 8 user's manual. Analytical software, Tallahassee
Bottenberg H, Tamò M, Arodokoun D, Jackai LEN, Singh BB, Youm O (1997) Population dynamics and migration of cowpea pests in northern Nigeria: implications for integrated pest management. In: Singh BB, Raj MDR, Dashiell KE, Jackai LEN (eds) Advances in cowpea research. Copublication of International Institute of Tropical Agriculture (IITA) and Japan International Research Center for Agricultural Sciences (JIRCAS). IITA, Ibadan, pp 271-284

Cardona C, Frei A, Bueno JM, Diaz J, Gu H, Dorn S (2002) Resistance to Thrips palmi (Thysanoptera: Thripidae) in beans. J Econ Entomol 95:1066-1073

Christou P, Capell T, Kohli A, Gatehouse JA, Gatehouse AMR (2006) Recent developments and future prospects in insect pest control in transgenic crops. Trends Plant Sci 11:302308. doi:10.1016/j.tplants.2006.04.001

Ehlers JD, Hall AE (1997) Cowpea (Vigna unguiculata L. Walp). Field Crops Res 53:187-204. doi:10.1016/S03784290(97)00031-2

Frei A, Blair MW, Cardona C, Beebe SE, Gu H, Dorn S (2005) QTL mapping of resistance to Thrips palmi Karny in common bean. Crop Sci 45:379-387

Hall AE, Singh BB, Ehlers JD (1997) Cowpea breeding. Plant Breed Rev 15:215-274

Hilder VA, Boulter D (1999) Genetic engineering of crop plants for insect resistance-a critical review. Crop Prot 18:177-191. doi:10.1016/S0261-2194(99)00028-9

Jackai LEN, Adalla CB (1997) Pest management practices in cowpea: a review. In: Singh BB, Raj MDR, Dashiell KE, Jackai LEN (eds) Advances in cowpea research. Copublication of International Institute of Tropical Agriculture (IITA) and Japan International Research Center for Agricultural Sciences (JIRCAS). IITA, Ibadan, pp 240258

Jackai LEN, Daoust RA (1986) Insect pests of cowpeas. Annu Rev Entomol 31:95-119. doi:10.1146/annurev.en.31. 010186.000523

Maris PC, Joosten NN, Peters D, Goldbach RW (2003) Thrips resistance in pepper and its consequences for the acquisition and inoculation of Tomato spotted wilt virus by the western flower thrips. Phytopathology 93:96-101. doi: 10.1094/PHYTO.2003.93.1.96

Morse JG, Hoddle MS (2006) Invasion biology of thrips. Annu Rev Entomol 51:67-89. doi:10.1146/annurev.ento.51. 110104.151044

Muchero W, Ehlers JD, Close TJ, Roberts PA (2009) Mapping QTL for drought stress-induced premature senescence and maturity in cowpea [Vigna unguiculata (L.) Walp]. Theor Appl Genet 118:849-863

Ngakou A, Tamò M, Parh IA, Nwaga D, Ntonifor NN, Korie S, Nebane CLN (2008) Management of cowpea flower thrips, Megalurothrips sjostedti (Thysanoptera: Thripidae), in Cameroon. Crop Prot 27:481-488. doi: 10.1016/j.cropro.2007.08.002

Omo-Ikerodah EE, Fawole I, Fatokun CA (2008) Genetic mapping of quantitative trait loci (QTLs) with effects on resistance to flower bud thrips (Megalurothrips sjostedti) identified in recombinant inbred lines of cowpea (Vigna unguiculata (L.) Walp). Afr J Biotechnol 7:263-270

Posthuma D, Luciano M, de Geus EJC, Wright MJ, Slagboom PE, Montgomery GW, Boomsma DI, Martin NG (2005) A 
genomewide scan for intelligence identifies quantitative trait loci on 2q and 6p. Am J Hum Genet 77:318-326. doi: $10.1086 / 432647$

Saidi M, Ngouajio M, Itulya FM, Ehlers J (2007) Leaf harvesting initiation time and frequency affect biomass partitioning and yield of cowpea. Crop Sci 47:1159-1166

Singh SR, Allen DJ (1980) Pests, diseases, and protection in cowpeas. In: Summerfield RJ, Bunting AH (eds) Advances in legume science. Royal Botanic Gardens/Ministry of Agriculture, Fisheries \& Food, Kew, London, pp 419-443

Stanton MA, Stewart MD, Tugwell NP (1992) Evaluation of Gossypium arboreum L. germplasm for resistance to thrips. Genet Resour Crop Evol 39:89-95

Stoner KA, Dickson MH, Shelton AM (1989) Inheritance of resistance to damage by Thrips tabaci Lindeman (Thysanoptera: Thripidae) in cabbage. Euphytica 40:233239

Timko MP, Ehlers JD, Roberts PA (2007) Cowpea. In: Kole C (ed) Genome mapping and molecular breeding in plants, vol 3. Pulses, sugar and tuber crops. Springer, Berlin, pp 49-68

Vales MI, Schön CC, Capettini F, Chen XM, Corey AE, Mather DE, Mundt CC, Richardson KL, Sandoval-Islas JS, Utz HF, Hayes PM (2005) Effect of population size on the estimation of QTL: a test using resistance to barley stripe rust. Theor Appl Genet 111:1260-1270. doi: 10.1007/s00122-005-0043-y

Van Ooijen JW, Voorrips RE (2001) JoinMap 3.0: software for the calculation of genetic linkage maps. Plant Research International, Wageningen

Van Ooijen JW, Boer MP, Jansen RC, Maliepaard C (2002) MapQTL ${ }^{2} 4.0$, software for the calculation of QTL positions on genetic maps. Plant Research International, Wageningen

Voorrips RE (2002) MapChart: software for the graphical presentation of linkage maps and QTLs. J Hered 93:7778. doi:10.1093/jhered/93.1.77

Walling LL (2000) The myriad plant responses to herbivores. J Plant Growth Regul 19:195-216 